\title{
Renal denervation reduces blood pressure in patients with treatment resistant hypertension
}

\author{
MARIA-CHRISTINA ZENNARO
}

Université de Paris, INSERM, PARCC, F-75015 Paris, France.

Assistance Publique-Hôpitaux de Paris, Hôpital Européen Georges Pompidou, Service de Génétique, Paris, France.

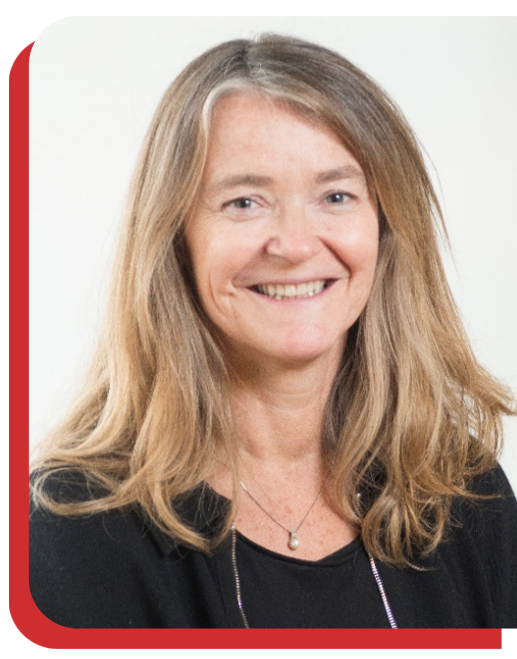

DOI: $10.30824 / 2110-3$

Endovascular renal denervation has been investigated as a novel antihypertensive treatment option for hypertensive patients. Previous clinical trials in the absence or presence of antihypertensive therapy have shown significant blood pressure reductions after renal denervation ${ }^{1}$. In particular, the RADIANCE-HTN SOLO trial 2 , showed the efficacy of renal denervation in patients with mild to moderate hypertension off-antihypertensive treatment during the initial 2-month trial period, with blood pressure lowering effect maintained at 6- and 12month post-intervention when patients were put back on medications. The RADIANCE- HTNTRIO ${ }^{3}$ trial aimed to assess the efficacy and safety of endovascular ultrasound renal denervation in patients with treatment resistant hypertension and to overcome previous methodological limitations in studies addressing renal denervation in this category of patients.

RADIANCE-HTN TRIO is a randomised, international, multicentre, single-blind trial in which 53 centres in Europe and USA, led by Michel Azizi from the Hôpital Européen Georges Pompidou, AP-HP in Paris, France, and Ajay Kirtane from Columbia University Medical Center/ New York-Presbyterian Hospital, NY, USA, enrolled 989 participants with treatment resistant hypertension aged 18-75 years with office blood pressure $>140 / 90$ $\mathrm{mmHg}$ on three or more antihypertensive medications including a diuretic. Patients were switched to a oncedaily single pill combination of a calcium channel blocker, an angiotensin-receptor blocker and a thiazide diuretic. After four weeks, 136 patients ( $80 \%$ men, mean age 52 years) with blood pressure $\geq 135 / 85 \mathrm{mmHg}$ were randomly assigned to endovascular ultrasound renal denervation or a sham procedure. The primary endpoint was the change in daytime ambulatory systolic blood pressure at 2 months. Full drug adherence to the combination therapy at two months, monitored by urine toxicological measurements, was high and similar in the two groups (82\%). After two months of follow-up, the daytime ambulatory systolic blood pressure was significantly reduced by $8 \mathrm{mmHg}$ in the denervation group, compared to the sham group $(-3.0 \mathrm{mmHg}$; median between- group difference $-4.5 \mathrm{mmHg}, 95 \%$ $\mathrm{Cl}-8.5$ to $-0.3 \mathrm{mmHg}$, adjusted $\mathrm{p}=0.022$ ). Changes of other blood pressure parameters were also in favour of renal denervation, including a significant reduction in 24-h ambulatory blood pressure, night-time ambulatory systolic blood pressure, and office and home systolic blood pressures. Moreover, 35\% of patients whose blood pressure was not controlled at randomisation had blood pressure normalisation two months after renal denervation compared to $21 \%$ in the in the sham group.

This study shows that ultrasound renal denervation significantly reduced blood pressure in patients with treatment resistant hypertension. Importantly, the study was designed to overcome potential biases and limitations. By using a single-pill triple combination and reducing pill burden, a high adherence to standard treatment was obtained. The blood pressure reductions observed in the RADIANCE-HTN TRIO trial are of a magnitude previously associated with a reduction in stroke, coronary heart disease, heart failure and allcause mortality ${ }^{4}$, which, if confirmed over the long term, may significantly reduce the cardiovascular burden in this high risk population. A follow-up at 6, 12 and 36 months is currently ongoing and will provide important information on the long-term effects of renal denervation and blood pressure reduction. Together with previous studies, these results suggest that catheter-based renal 
denervation efficiently lowers blood pressure across the spectrum of hypertension severity, possibly providing an alternative treatment option in high-risk patients with hypertension.

\section{References}

1. Sardar P, Bhatt DL, Kirtane AJ, Kennedy KF, Chatterjee S, Giri J, Soukas PA, White WB, Parikh SA, Aronow HD. Sham-Controlled Randomized Trials of Catheter-Based Renal Denervation in Patients With Hypertension. J Am Coll Cardiol. 2019;73:1633-1642.

2. Azizi M, Schmieder RE, Mahfoud F, Weber MA, Daemen J, Davies J, Basile J, Kirtane AJ, Wang Y, Lobo MD, Saxena M, Feyz L, Rader F, Lurz P, Sayer J, Sapoval M, Levy T, Sanghvi K, Abraham J, Sharp ASP, Fisher NDL, Bloch MJ, ReeveStoffer H, Coleman L, Mullin C, Mauri L, Investigators $\mathrm{R}-\mathrm{H}$. Endovascular ultrasound renal denervation to treat hypertension (RADIANCE-HTN SOLO): a multicentre, international, single-blind, randomised, sham-controlled trial. Lancet. 2018;391:2335-2345.
3. Azizi M, Sanghvi K, Saxena M, Gosse P, Reilly JP, Levy T, Rump LC, Persu A, Basile J, Bloch MJ, Daemen J, Lobo MD, Mahfoud F, Schmieder RE, Sharp ASP, Weber MA, Sapoval M, Fong P, Pathak A, Lantelme P, Hsi D, Bangalore S, Witkowski A, Weil J, Kably B, Barman NC, Reeve-Stoffer $\mathrm{H}$, Coleman L, McClure CK, Kirtane AJ, investigators R-H. Ultrasound renal denervation for hypertension resistant to a triple medication pill (RADIANCE-HTN TRIO): a randomised, multicentre, single-blind, sham-controlled trial. Lancet. 2021;397:2476-2486.

4. Ettehad D, Emdin CA, Kiran A, Anderson SG, Callender T, Emberson J, Chalmers J, Rodgers A, Rahimi K. Blood pressure lowering for prevention of cardiovascular disease and death: a systematic review and metaanalysis. Lancet. 2016;387:957-967.
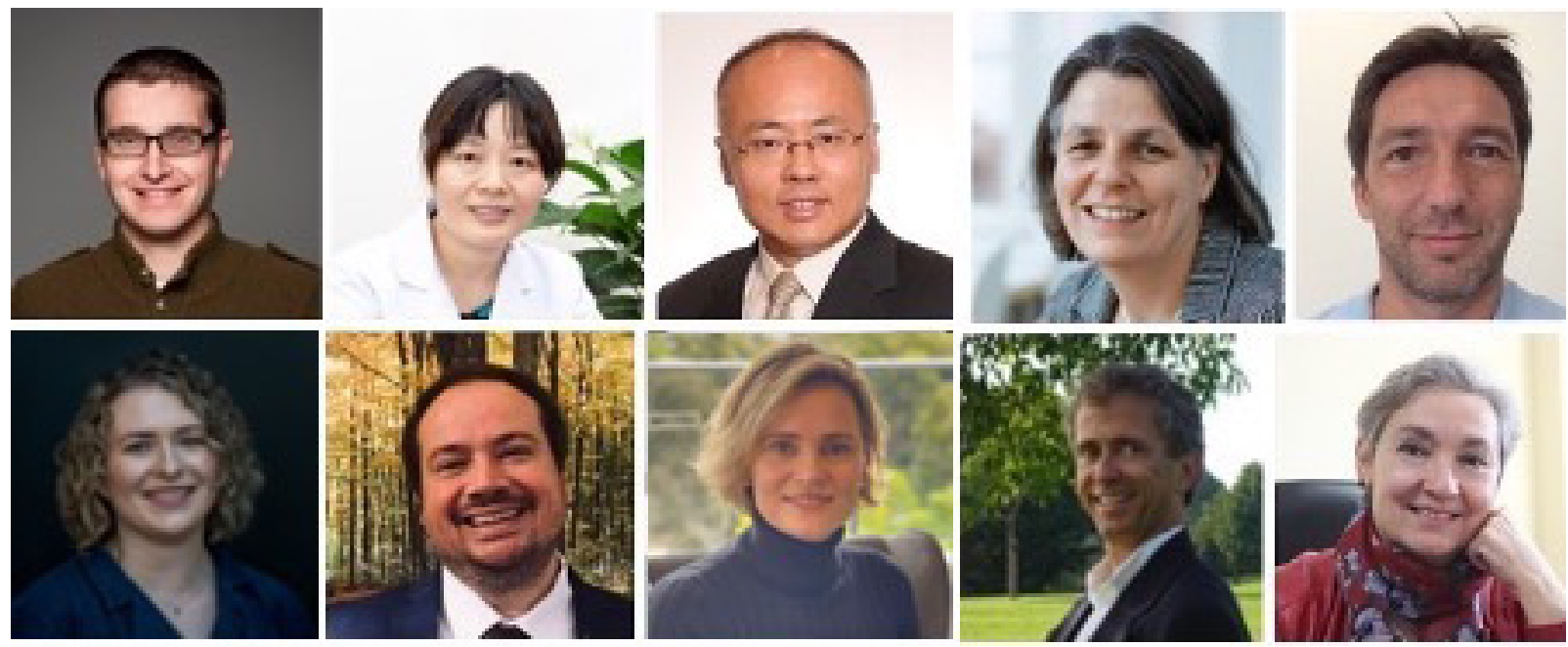

Online Mentoring Meetings October 2021
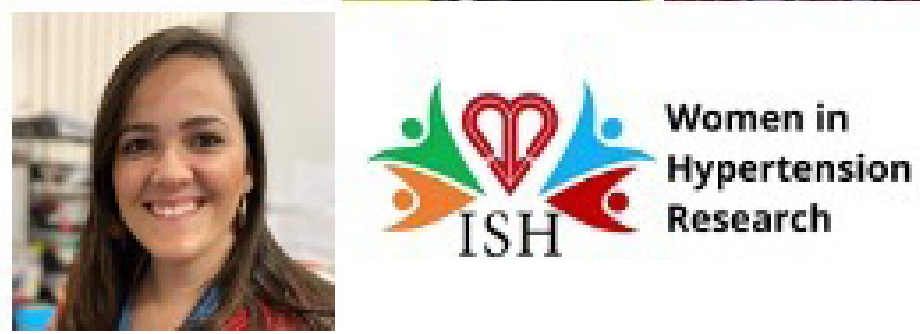